\title{
Squamous Cell Carcinoma Kidney in a Patient of Renal Calculi: Rare and Aggressive Variant of Renal Cancer
}

\author{
Syed Mehmood Hasan ${ }^{1}$, Talat Zehra ${ }^{1}$, Salma Parween ${ }^{1}$, and Sadaf Razzak ${ }^{1}$
}

\begin{abstract}
Squamous Cell Carcinoma (SCC) of kidney is a rare presentation. It behaves aggressively in case of kidney. It is usually diagnosed at an advance stage and has a poor prognosis. Renal squamous cell carcinoma is usually associated with stones. Chronic irritation due to stone causes metaplasia of lining epithelium resulting in transformation of squamous cell carcinoma which is rare but the most fatal complication. Here we are presenting a case of renal squamous cell carcinoma associated with stones.

How to cite this article: Hasan SM, Zehra T, Parween S, Razzak S. Squamous cell carcinoma kidney in a patient of renal calculi: rare and aggressive variant of renal cancer.

Ann Jinnah Sindh Med Uni 2020; 6(1):29-30

DOI:https://doi.org/10.46663/ajsmu.v6i1.29-30
\end{abstract}

\section{INTRODUCTION}

Squamous cell carcinoma is a very rare tumour which makes up under $1 \%$ of all malignant tumours of kidney. This tumour is very aggressive in nature and prognosis is poor because it is usually diagnosed in advance stage $^{1}$. Risk factors leading to renal squamous cell carcinoma include renal calculi, infection, endogenous and exogenous chemicals, vitamin A deficiency, hormonal imbalance, and radiotherapy ${ }^{2}$.

\section{Case presentation:}

A 63-years-old female presented to the urology ward of a tertiary care unit with the complaint of renal stones for seven years with flank pain. Ultrasound kidney showed kidney with features of hydronephrosis and multiple renal stones. She underwent nephrectomy. The specimen was sent for histopathological examination in $10 \%$ buffered formalin. On gross examination, the specimen was previously (surgically) distorted and fragmented. On further slicing, there were features of hydronephrosis, thinned out corticomedullary areas and most of the other areas revealed gray white cut surface with friable to cut areas as shown in photograph 1 . The collective dimensions of the fragment are $15 \times 10 \times 4 \mathrm{cms}$. Histological

1 Department of Pathology, Sindh Medical College, Jinnah Sindh Medical University, Karachi, Pakistan

.............................................

Correspondence: Professor Syed Mehmood Hasan, Head Department of Pathology, Sindh Medical College, Jinnah Sindh Medical University, Karachi, Pakistan

Email:mehmood.hasan@jsmu.edu.pk examination revealed a malignant neoplastic lesion comprising of a nest of squamous carcinomatous components with keratin pearl formation. Few glomeruli and tubules were also observed at the periphery intermixed with neoplastic lesions as showed in the photomicrograph 2 and 3 . There was a dense to diffuse mixed inflammatory infiltration and areas of necrosis were also seen in the interstitium.

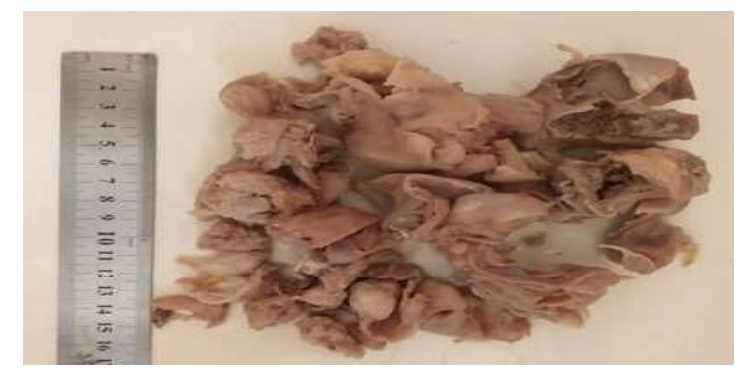

Photograph 1: The gross examination of received sample exhibiting fragments of kidney with solid to cystic areas

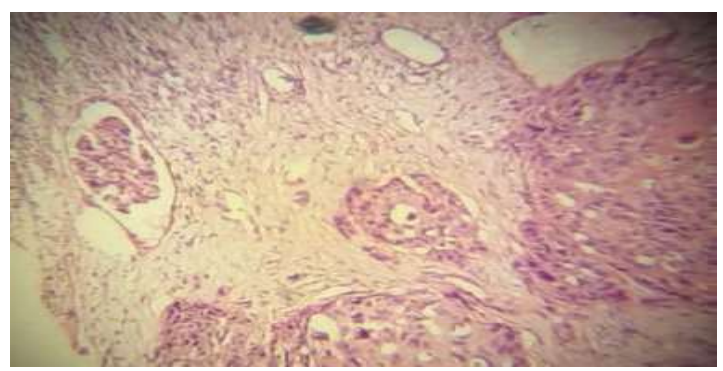

Photograph 2: The histopathological image showing with an invasive squamous cell carcinoma on the right side of this field distorting the renal architecture with a single glomerulus of the left side of the field is identified. X 100 


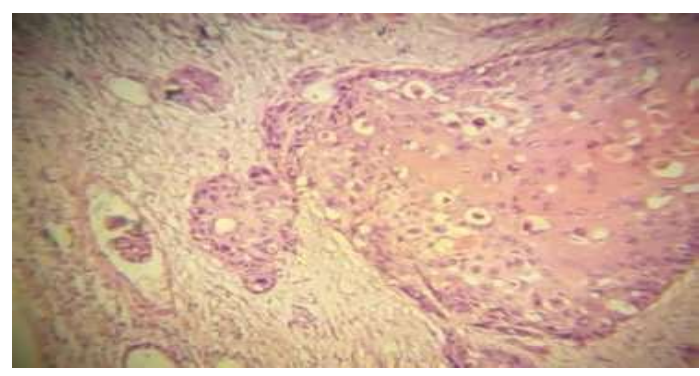

Photomicrograph 3: The histopathological image showing a fibrosed glomerulus of the left side of the field surrounded by scattered inflammatory cells in the interstitium with invasive squamous cell carcinoma on the right side. X 100

\section{DISCUSSION}

Renal squamous cell is extremely rare. Bladder and male urethra are its more common sites than the renal pelvis ${ }^{3}$. Histologic hallmarks of renal SCC include intercellular bridges, pearl formation, and keratotic cellular debris ${ }^{4}$. Possible carcinogenic mechanisms for SCC of the renal pelvis have been proposed. Chronic irritation of urothelium may result in squamous metaplasia, which if persistent, may later develop into SCC. SCCs of the kidney are frequently associated with renal stones, hydronephrosis and chronic infection, all of which contribute to chronic irritation and subsequent development of squamous metaplasia in the neighboring epithelium ${ }^{5}$. Renal SCC usually presents at an advanced stage with extensive local infiltration and has a poor prognosis ${ }^{6}$. Primary SCC has a slight female preponderance occurring most commonly in the age group of 50-70 years ${ }^{7}$. Studies show that SSC generally spreads locally with associated symptoms of regional lymphadenopathy. Cases have been reported with metastasis to the lungs, liver, and bone. SCC is a highly aggressive tumour. It has the worst prognosis among histological subtypes of renal pelvis tumours. Its median survival rate is 3.5 months $^{9}$.

\section{CONCLUSION}

Renal SCC is a very rare entity. Its insidious onset and nonspecific radiological findings permit late diagnosis resulting in poor prognosis. These tumours are usually treated with aggressive surgery and chemo radiation in case of metastatic disease. The possibility of primary renal SCC should be considered in cases of nonfunctioning kidney with renal stones after ruling out metastatic disease with the help of clinical and radiological findings.
Authors' contribution: Syed Mehmood Hasan worked on histopathological diagnosis and details. Talat Zehra conceived the idea and wrote the manuscript. Salma Parween and Sadaf Razzaq carried out the literature search.

\section{References}

1. Salehipour M, Dastgheib N, Hosseinzadeh M, Makarem A, Rezvani A, Sanati A, et.al. Primary renal pelvis and ureter squamous cell carcinoma (SCC): a rare case report and review of literature. Int Med Case Rep J. 2019; 12:189-192. doi: 10.2147/IMCRJ.S203283. eCollection 2019.

2. Jiang P, Wang C, Chen S, Li J, Xiang J, Xie L. Primary renal squamous cell carcinoma mimicking the renal cyst: a case report and review of the recent literature. BMC Urol. 2015; 69:15. doi:10.1186/s12894-015-0064-Z

3. Obad-Kovaèeviæ D, Kardum-Skelin I, Kaiæ G, JeliæPuškariæ B, Kovaèeviæ K. Hydronephrotic Kidney Previously Treated for Tuberculosis: Rare Primary Squamous Cell Carcinoma of Renal Pelvis Diagnosed by Fine-needle Aspiration Cytology. Urol Case Rep. 2015;3(5):173-174. doi:10.1016/j.eucr.2015.06.013

4. Hippargi SB, Nerune SM, Kumar M. Urothelial and Squamous Cell Carcinoma of Renal Pelvis - A Rare Case Report. J Clin Diagn Res. 2016; 10(9): ED19-ED20. doi:10.7860/JCDR/2016/20860.8576

5. Ogawa M, Morikawa T, Toyoshima T, Fukayama M. Squamous cell carcinoma in a duplicated renal pelvis. Int J Clin Exp Pathol. 2014;7(11):7957-7961.

6. Deng S, Zhang B, Huang Y, Li J, Sang S, Zhang W. Case report of primary renal pelvis squamous cell carcinoma coexisting with long-standing calculi in left kidney on 18F-FDG PET/CT. Medicine (Baltimore). 2017; 96(11): e6341. doi:10.1097/MD. 000000000000 6341

7. Hameed ZB, Pillai SB, Hegde P, Talengala BS. Squamous cell carcinoma of the renal pelvis presenting as sacral bone metastasis. BMJ Case Rep. 2014; 2014: bcr2013201719. doi:10.1136/bcr-2013-201719

8. Kim JR, Jeong YB, Lee NH, Wang SI. Squamous cell carcinoma of the renal pelvis presenting as an integumentary neoplasm of the flank: A case report. Medicine (Baltimore) . 2019; 98(36):e17049. doi:10. 1097/MD.0000000000017049

9. Obad-Kovaèeviæ D, Kardum-Skelin I, Kaiæ G, JeliæPuškariæ B, Kovaèeviæ K. Hydronephrotic Kidney Previously Treated for Tuberculosis: Rare Primary Squamous Cell Carcinoma of Renal Pelvis Diagnosed by Fine-needle Aspiration Cytology. Urol Case Rep. 2015;3(5):173-174. doi:10.1016/j.eucr.2015.06.013 